\title{
Notes on the vocalizations of White-rumped Shama (Copsychus malabaricus)
}

Peter Boesman

In the following we briefly analyze and compare voice of the different races of White-rumped Shama (Copsychus malabaricus). We also try to quantify the extent of any vocal differences using the criteria proposed by Tobias et al. (2010), as a support for taxonomic review.

We have made use of sound recordings available on-line from Xeno Canto (XC).

Our main interest is to compare albiventris from the Andaman Islands with the mainland races. Some examples of song:

Andaman islands (albiventris) $(n=4)$

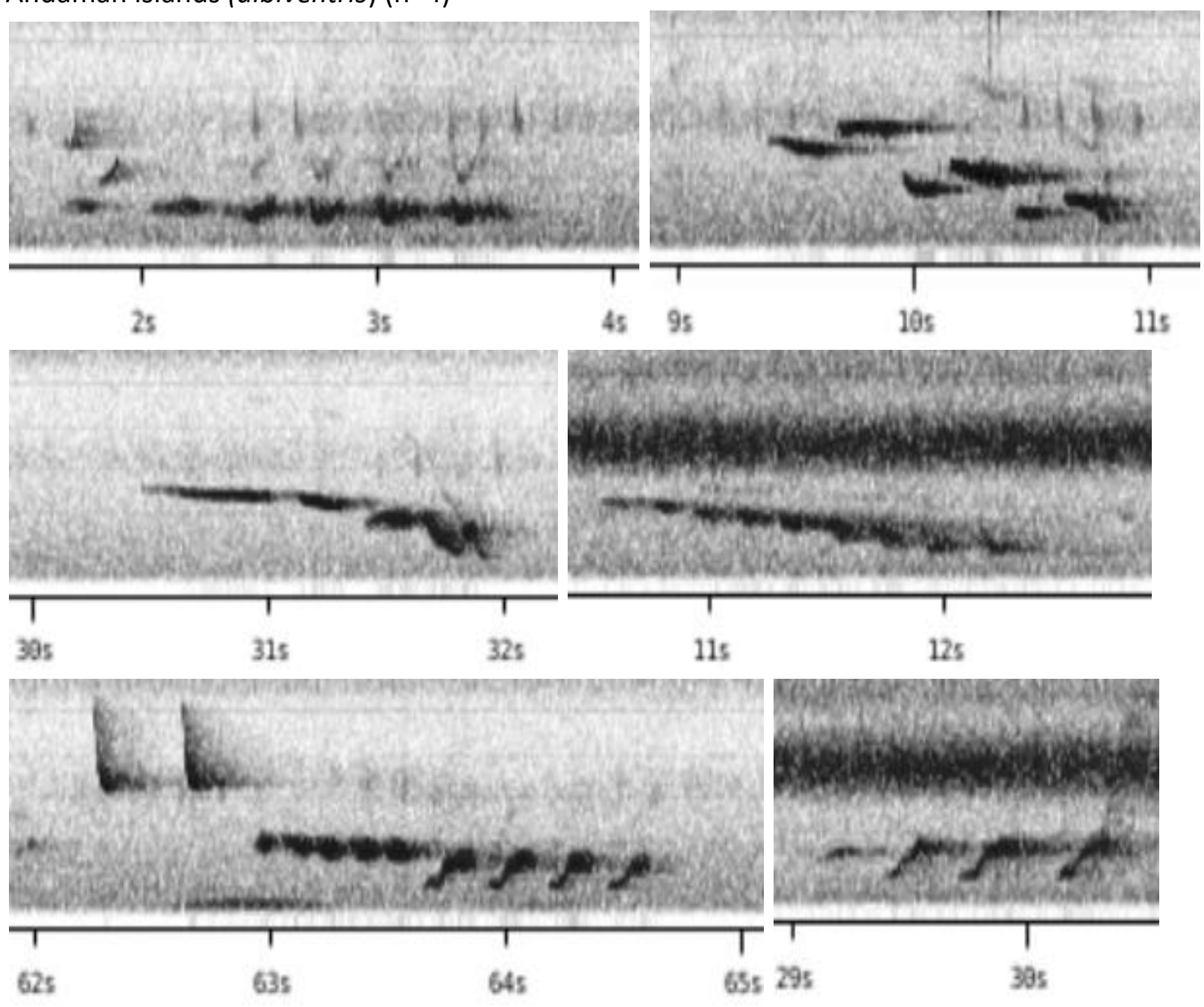




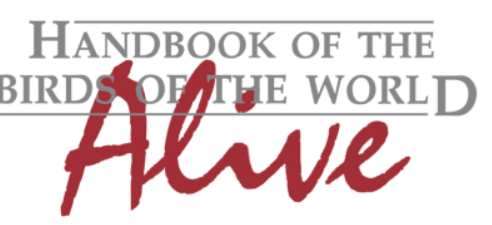

\section{ORNITHOLOGICAL NOTES}

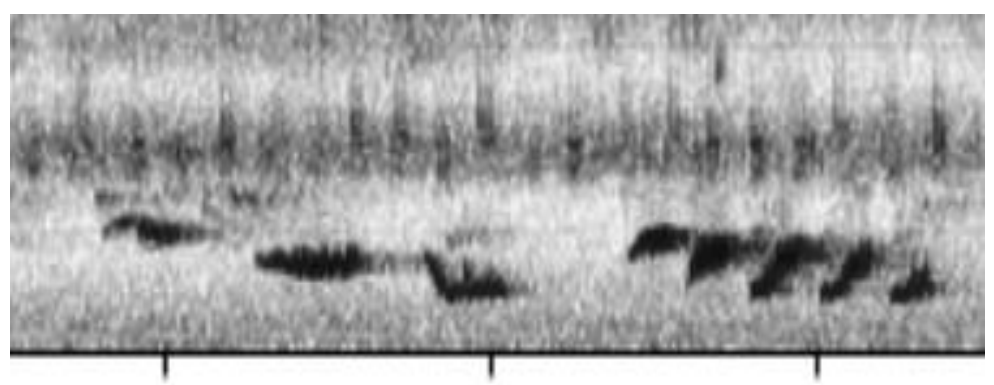

25 35 45

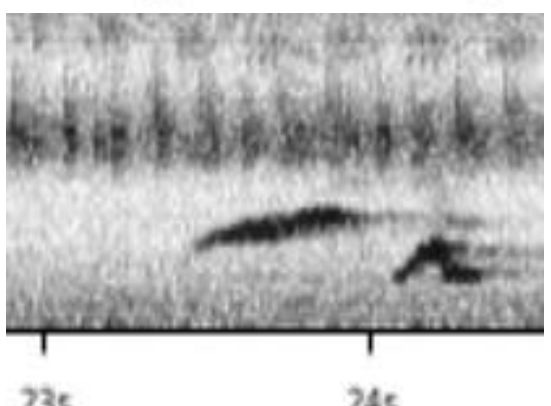

$23 s$

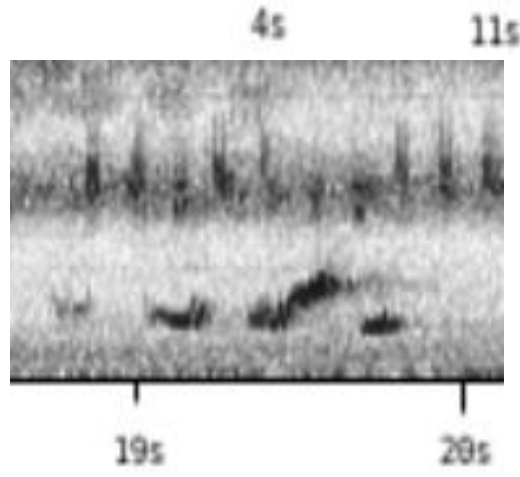

Some examples of other races (from short to long song phrases):
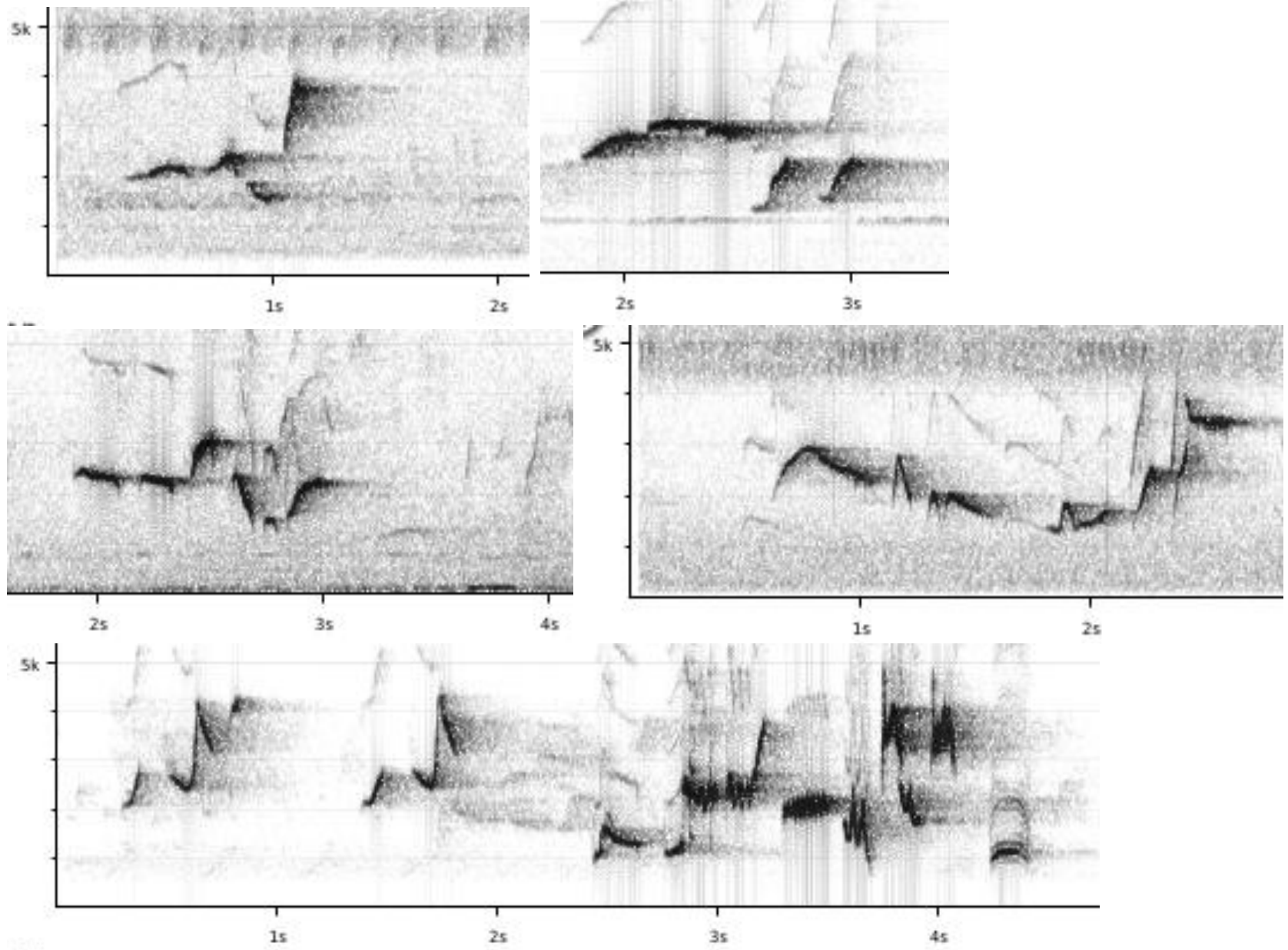

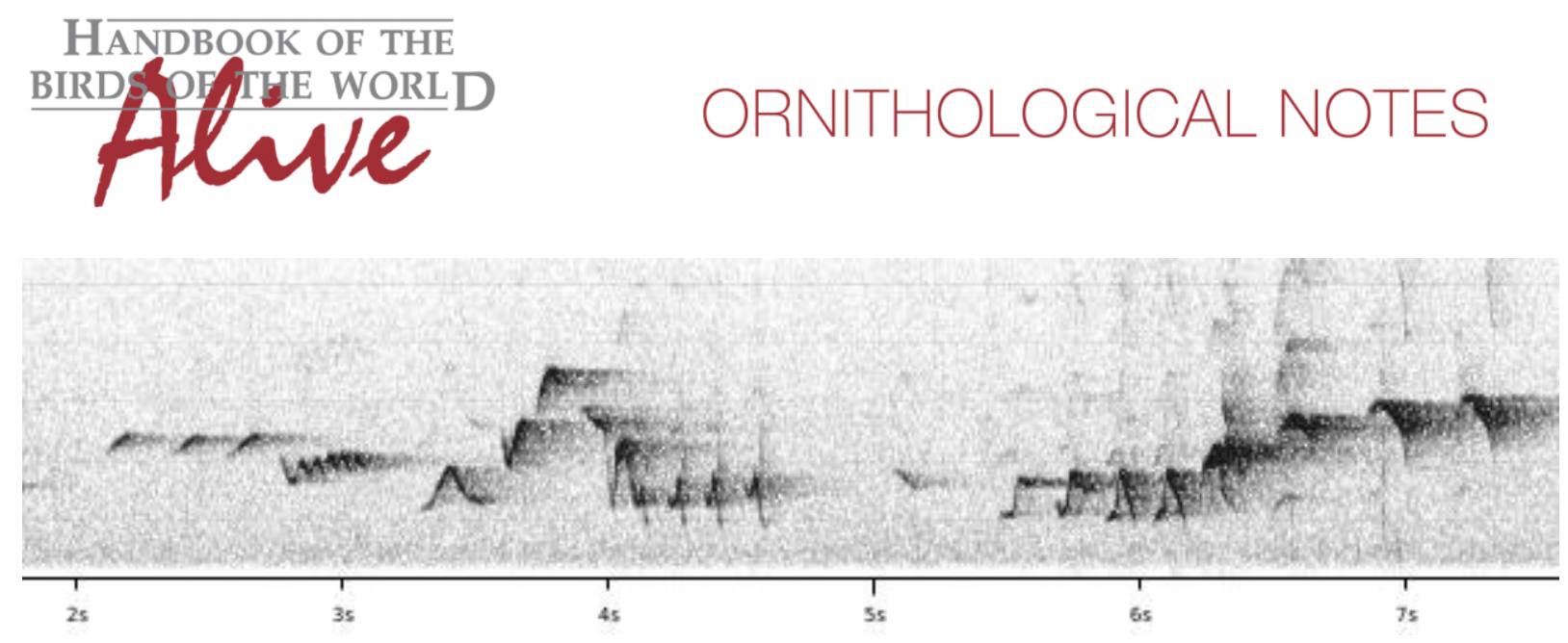

From the above examples, it would seem that albiventris differs from other races by:

* on average lower min. frequency (all song strophes reach $1 \mathrm{kHz}$ or lower, in other races only about half of the song strophes reach $1 \mathrm{kHz})$-> score 1

* on average lower max. freq.: rarely above $3 \mathrm{kHz}$ vs. almost always above $3 \mathrm{kHz}->$ score $1-2$

* song phrase seems to end always with a low frequency whistle (usually the lowest of all) vs. last whistle very often medium or high-pitched and only occasionally the lowest of all (score 2)

* song phrases on average are shorter with less notes (score 1)

Above findings concur with vocal differences described in The Ripley Guide (Rasmussen \& Anderton 2012)

Based on lower pitch (min. and max. frequency (score 1-2), shorter phrases with less notes on average (score 1) and end of song phrase always low-pitched (score 2), application of Tobias criteria would lead to a total vocal score of 3-4.

A voice comparison of all races separately may reveal more information on vocal differences, but would require a more extensive analysis, and in any case, when searching for more subtle differences, a larger set of recordings of albiventris (and some other races) would be required.

This note was finalized on 6th May 2016, using sound recordings available on-line at that moment. We would like to thank in particular the many sound recordists who placed their recordings for this species on XC, and especially Brian Cox and Gerard Gorman for recordings of albiventris.

\section{References}

Rasmussen, P.C. \& Anderton, J.C. (2012). Birds of South Asia: the Ripley Guide. Second Edition. Lynx Edicions, Barcelona.

Tobias, J.A., Seddon, N., Spottiswoode, C.N., Pilgrim, J.D., Fishpool, L.D.C. \& Collar, N.J. (2010). Quantitative criteria for species delimitation. Ibis 152(4): 724-746. 


\section{Recommended citation}

Boesman, P. (2016). Notes on the vocalizations of White-rumped Shama (Copsychus malabaricus). HBW Alive Ornithological Note 314. In: Handbook of the Birds of the World Alive. Lynx Edicions, Barcelona. (retrieved from http://www.hbw.com/node/1251832 on 18 October 2016). 